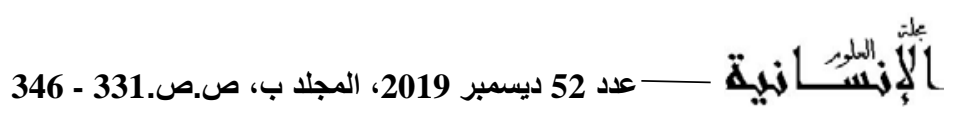

\title{
تقييد الحرية التعاقدية لمصلحة المستهلك
}

Restricting contractual freedom in the interest of the consumer

2019/11/24: تاريخ الاستلام :2019/10/26؛ تاريخ القبول

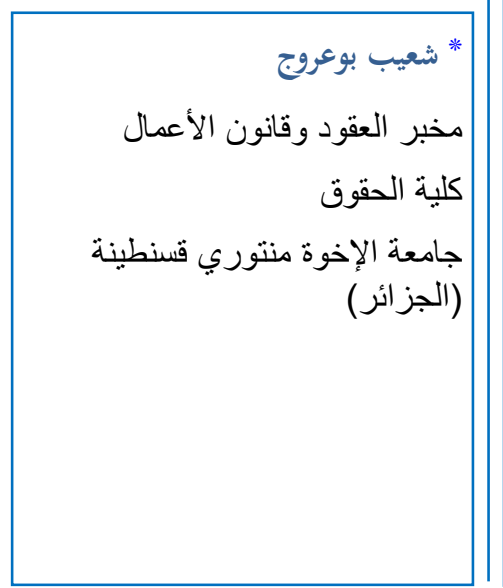

\section{Abstract}

everybody new that the contract of consumption is a contract not marked with economic balance between thé consumer ans the intervention, ans for this reason the algerian legislator by restriction of freedom of the economic intervention because he is the strong part un the contract, as a protection for the benefit of the consumer that is the weakest part

ans this study comes to search in this restricted intervention to the principle of contractual freedom ans how effective it is in the benefit of the consumer.

Keywords:the restriction, the contractual freedom, the intervention, the consumer, contract of consumption.

\section{Résumé}

Tout le monde sait que le contrat de consommation est un contrat sans équilibre économique entre ses parties " le consommateur et le professionnel ", c'est pourquoi le législateur algérien est intervenus pour remédier à cette situation en limitant la liberté de l'intervenant économique car c'est la partie la plus forte dans la relation du consommation, cela protégera les intérêts du consommateur qui est la partie la plus faible dans cette relation.

Donc, cette étude à porter sur cette intervention restrictive du principe de la liberté contractuelle et son efficacité dans la protection du consommateur.

Mots clés: restriction, la liberté contractuelle, l'intervention, le consommateur, le contrat de consommation.

*Corresponding author, e-mail:chouaib.bouarroudj@umc.edu.dz 
مقدمة:

لا أحد يجرأ على القول بأن المستهلك لا يحتاج إلى حماية قانونية شاملة, فالكل يتفق

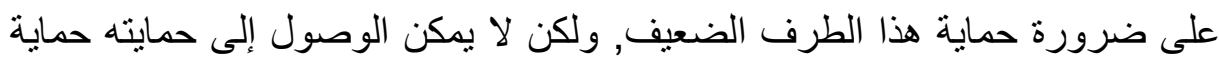

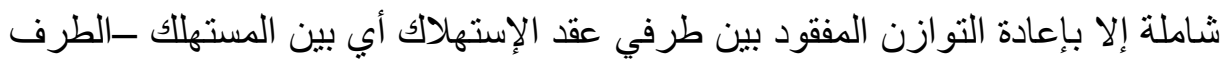

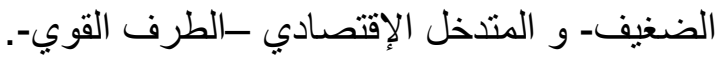

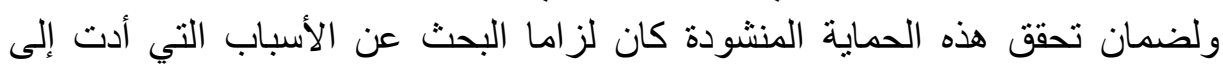

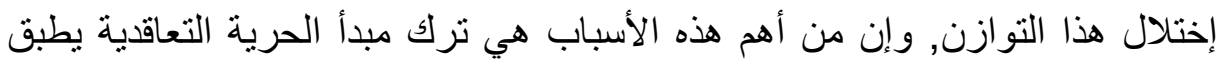

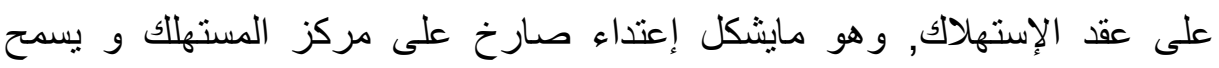
بإختلال التوازن العقدي أكثر فأكثر و يؤثر سلبا على الطرف الضئن الضعيف بل و و يجعله

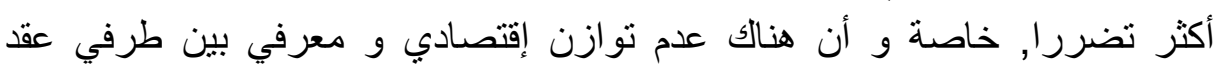
الإستههلك.

وقد تفطن المشرع الجزائري إلى ذلك وتدخل بتقييد حرية المتدخل الإقتصادي, وهذا

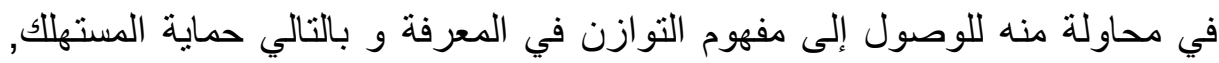
وهو الأمر الذي يدعو إلى التساؤل حول: كيف تلخل المشرع الجزائري للحد من مبأ الحرية التعاقدية؟ وما مدى نجاعة التهائ هذا التلاخل في حماية المستهلك؟.

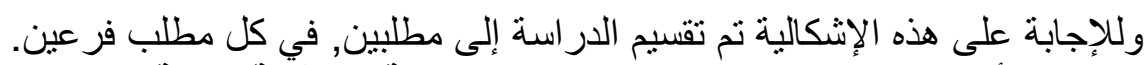

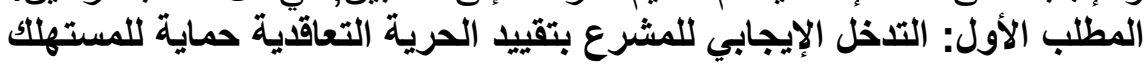
المطلب الثاني: التدخل السلبي للمشرع بتقيبد الحرية التعاقدية حماية للمستهلك

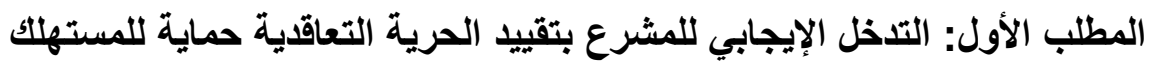

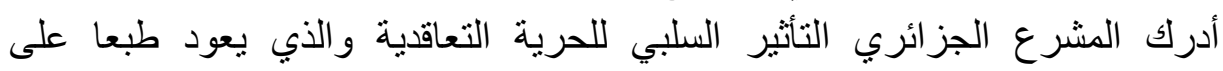

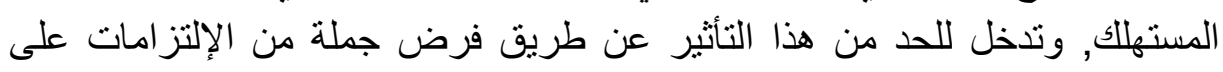
عاتق المتدخل, يلتزم بها طيلة فترة التعاقد ومنها مايلتزم بها حتى بلى بعد التعاقد.

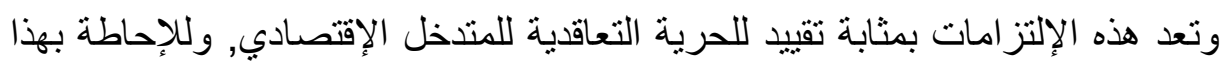

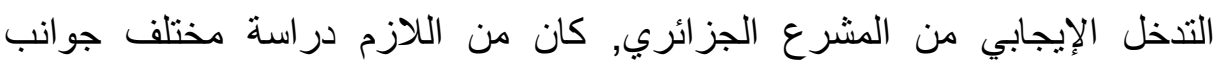

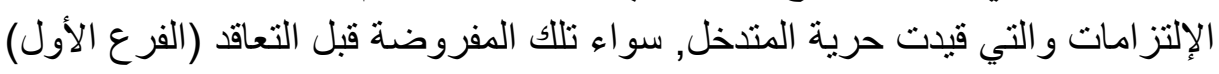
أو بعده (الفرع الثاني).

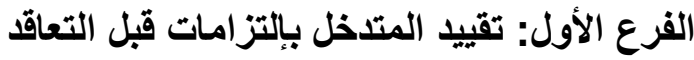

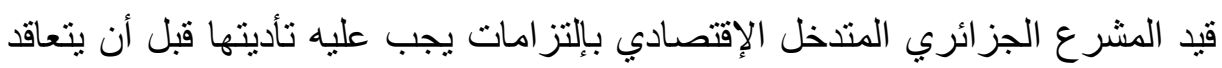

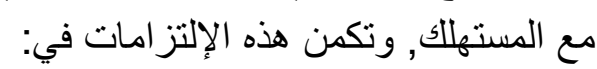
إلزامية النظافة و النظافة الصحية للمواد الغذائية و سلامتها (أولا) وكذا إلزامية امية أمن

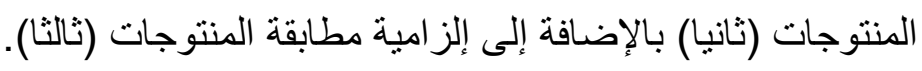

أولا: تقييد المتلخل بإلزامية النظافة و النظافة الصحية للمواد الغذائية و سلامتها التها لقد نص المشرع الجزائري على هذا الإلتزام بدءا من المادة 4 إلى غاية المادة 8 من 
الأمر 03-03 المتعلق بحماية المستهلك و قمع الغش(1), ويتضمن هذا الإلتزام عنصرين, عنصر النظافة الصحية للمادة الغذائية و عنصر سلامة هذه المادة وسيتطرق إليهما من منظور أنهما يقيدان حرية المتدخل الإقتصادي. 1-تقييد المتدخل بإلزامية النظافة و النظافة الصحية للمواد الغذائية:

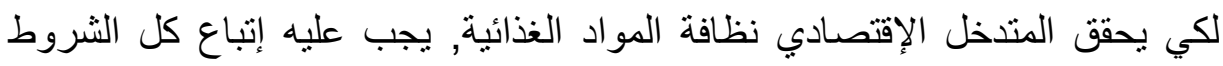

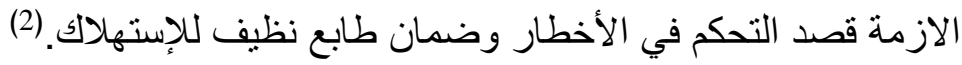
وتتمثل هذه الثروط أساسا في السهر على النظافة الصحية للمستخدمين, وللأماكن و محلات التصنيع, وكذا السهر على نظافة وسائل النقل(3). ونجد المشرع الجزائري أهمل التطرق للنظافة الخاصة بالمادة الأولية وهذا في قانون

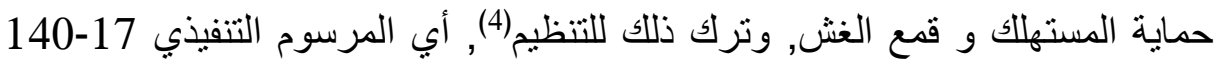
و الذي ألغى المرسوم التنفيذي رقم 91-51 المتعلق بالثروط الصحية المطلوبة عند عملية عرض الأغذية للإستهلاك(5).

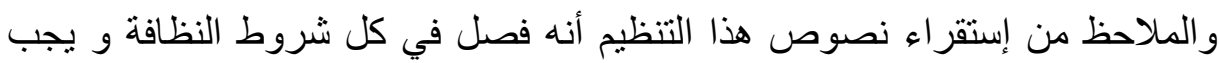

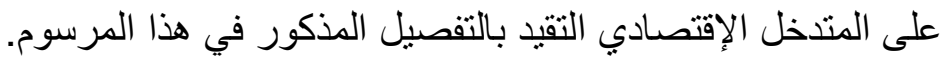
2- تقييا المتلخل بإلزامية سلامة المادة الغذائية:

لكي يحقق المتدخل سلامة المادة الغذائية يجب عليه السهر على أن لا تضر بصحة المستهلك(6), ويتحقق هذا عن طريق تقيده بالمرسوم التنفيذي رقم 15-172 المحدد للشروط و الكيفيات المطبقة في مجال الخصائص المكروبيولوجية للمواد الغذائية(7), كما يجب عليه أن يسهر على عدم إحتواء المواد الغذائية على ملوث بكمية غير مقبو لة)(8). و الملوث هو كل مادة تظاف بغير قصد في الغذاء, ولكن توجد فيه على شكل بقايا في الإنتاج(9), كما أن الحد الأقصى لملوث موجود في منتوج موجه للإستهلاك البشري أو لؤئي

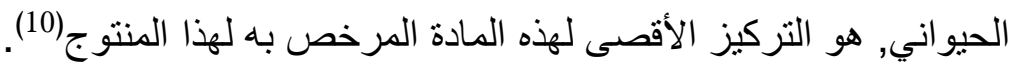

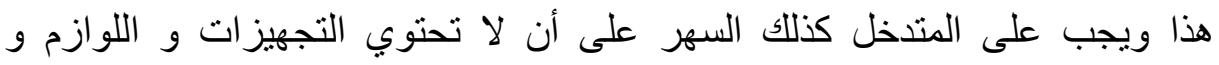

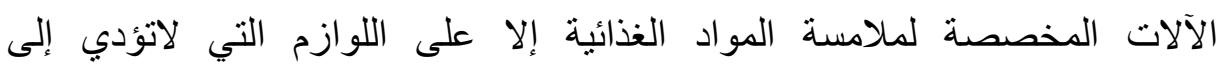

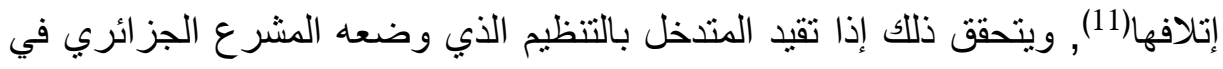
هذا الإطار, أي بالمرسوم التنفيذي 04-210 الذي يحدد المواصفات التقنية للمغلفات(12), و المرسوم التنفيذي 91-04 والذي يتعلق بالمواد المعدة لكي تلامس بلإس الأغذية و مستحضر ات التنظيف(13).

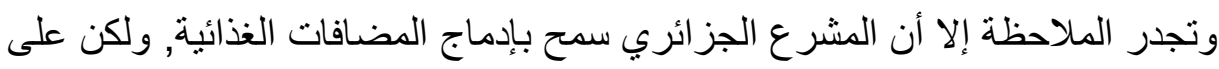
المتدخل إحترام شروط و كيفيات إستعمالها(14), ويتحقق هذا الإحتر ام إذا تقيد المتدخل بالمرسوم التنفيذي 12-214 المحدد لهذه الثروط و الكيفيات(15). و الملاحظ من هذا الإلتزام أنه إلتزام يحتوي على كثير من النصوص القانونية و 
التنظيمية التي تقيد الحرية التعاقدية للمتدخل الإقتصادي إلى حد معتبر.

ثانيا: تقييا المتلخل بإلزامية أمن المنتوجات

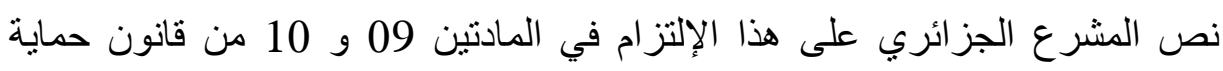
المستهلك و قمع الغش. ويفهم من خلال إستقراء نص المادة 09 أن المنتوج الموضوع للتداول و الإستهلاك

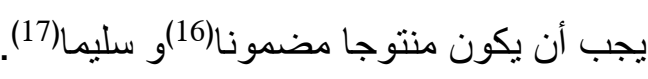

أما المادة 10 فبينت النطاق الذي يتقيد به المتنخل في تتفيذه لهذا الإلتز ام بقولها :

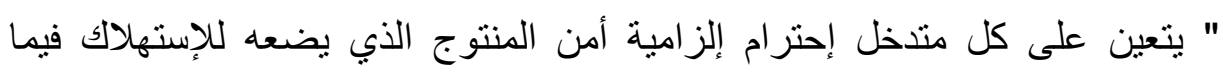

$$
\text { -مميز اته و تركيبته و تغليفه وشروط تجميعه و صيانته. }
$$

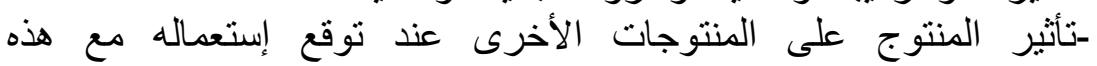

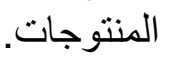

-عرض المنتوج و وسمه و التعليمات المحتملة الخاصة بإستعماله و إتلافه و الماتهات كذا كل الإرشادات أو المعلومات الصنات الصنادرة عن المنتج.

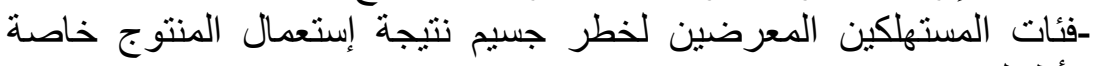
الأطفال.

تحدد القواعد المطبقة في مجال أمن المنتوجات عن طريق التنظيم".

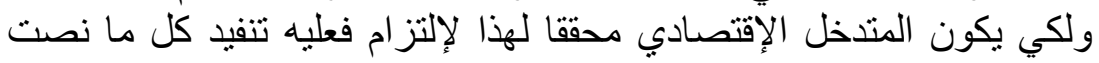

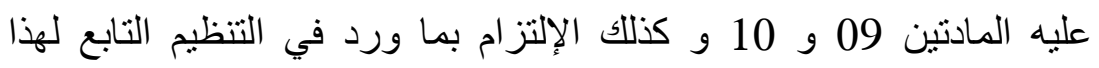
الإلتز ام, أي بنصوص المرسوم التنفيذي

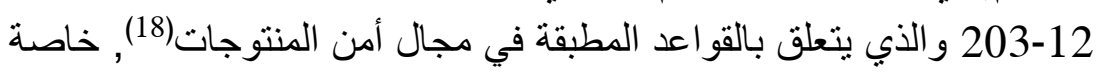
و أنه يبين نطاق الإلتز ام بأمن المنتوجات بالتفصيل.

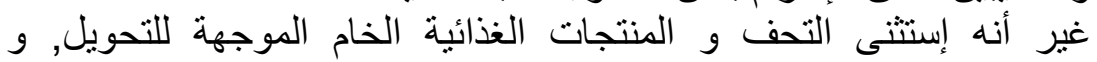

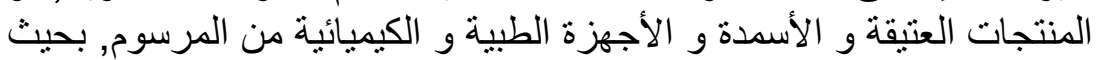

$$
\text { تخضع لأحكام تشريعية خاصة (19). }
$$

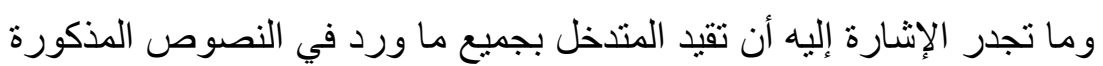

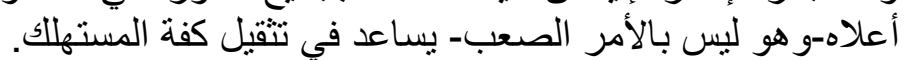

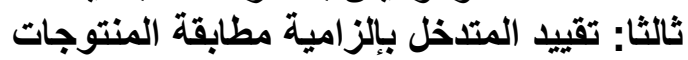

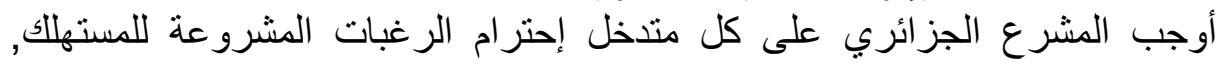

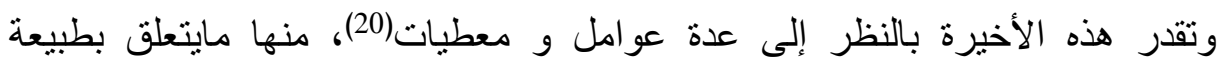

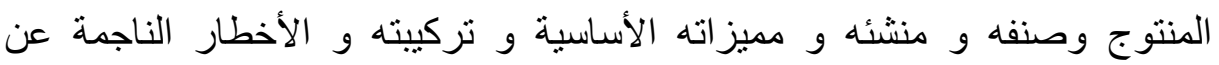

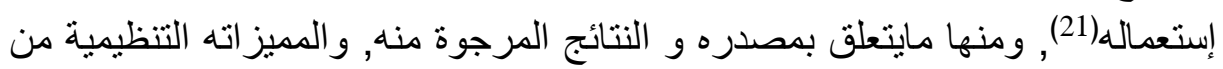
ناحية تغليفه و تاريخ صنعه و التاريخ الأقصى لإستهلاكه(22.

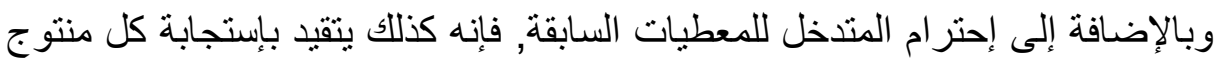
يضعه للإستهلاك للشروط المترم المنضمنة في اللوائح الفنية و للمتطلبات كنات الصحية و البيئية و

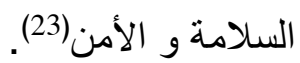


ويقصد باللائحة الفنية كل وثثقة تنص على خصائص منتوج ما, أو العمليات وطرق

الإنتاج المرتبطة به بما في ذلك النظام المطبق عليها, ويكون إحتر امها إلز اميا(24).

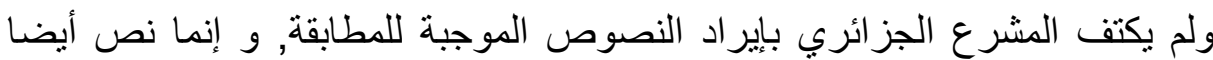

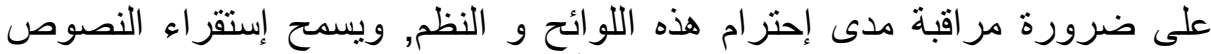
القانونية بالقول بوجود نوعين من الرقابة, الأولى رقابة ذاتية يقوم بها المحترف نفسه

و الثانية رقابة إدارية تقوم بها الجهات الإدارية المختصة وهن وهي مكملة للأولى (25). و هذه الرقابة إجبارية بنص المادة 12 من قانون حماية المستهلك و قمع الغش, لأن من خلالها يتم التأكد من أن ما تم التخطيط له هو ما تم تتفيذه و التقبد به(26). الفرع الثاني: تقييد المتذخل بإلتزامات أثناء و بعد التعاقد

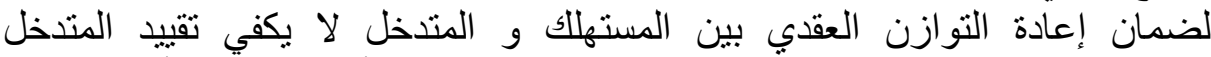

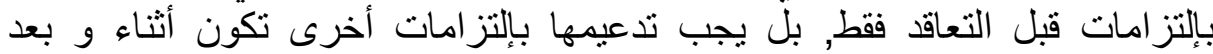

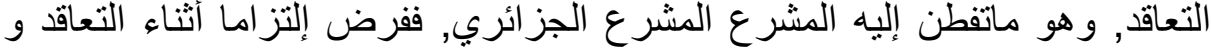

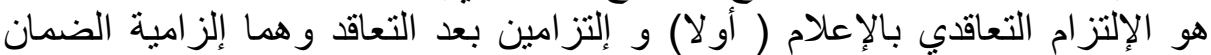

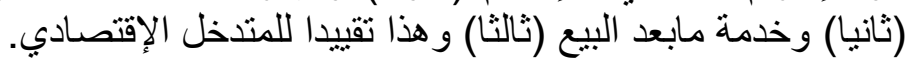

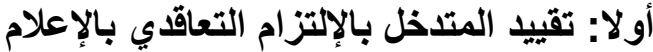

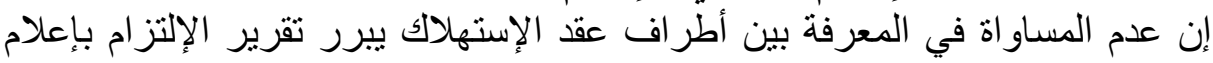

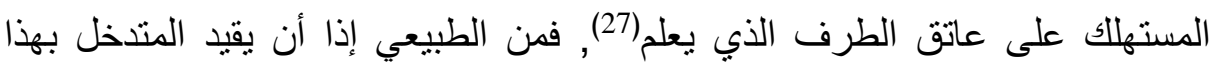

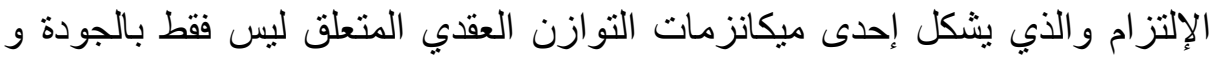

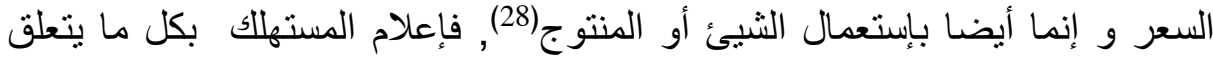
بالمنتوجات محل التعاقد يعد أمرا هاما, لأنه يسهم في تعميق معارفه و حقوقهاب(29),

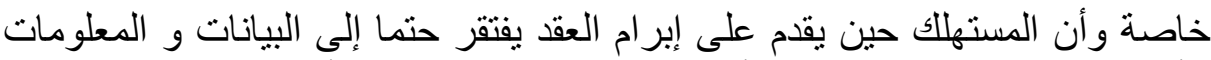

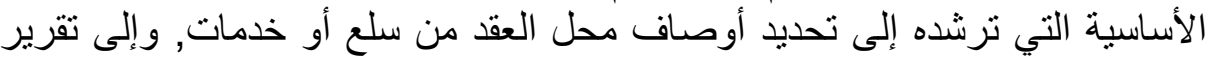

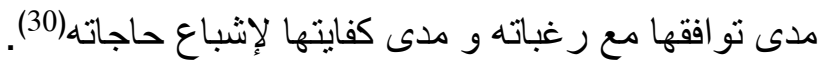
ولهذا أوجب المشرع الجزائري على كل متدخل أن بعلى بعلم المستهلك بكل المعلومات

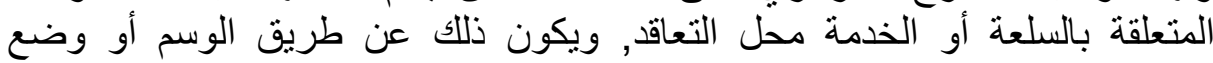
العلامة أو أية وسيلة أخرى مناسبة(31).

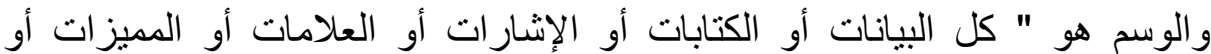

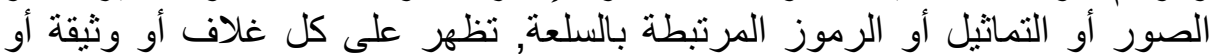
لافتة أو سمة أو ملصقة أو بطاقة أو ختم أو أو معلقة مرفقة الو أو أو دالة على على طبيعة منتوج مهما كان شكلها أو سندها, بغض النظر عن طريقة وضة وضعها.

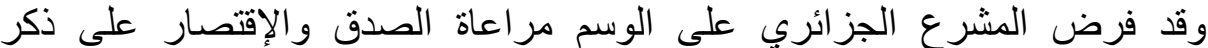

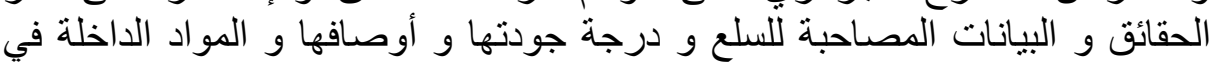

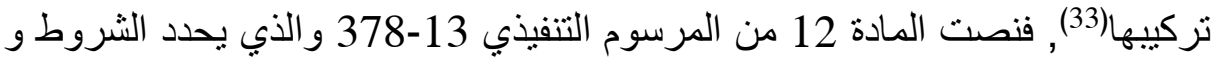
الكيفيات المتعلقة بإعلام المستهلك(34) على البيانات الإلزامية لوسم المواد الغذائية, و كذا المادة 38 و التي نصت على البيانات الإلز امية لوسم المواد غير الغذائية.

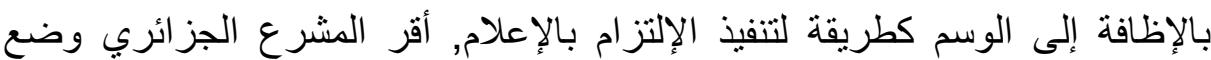

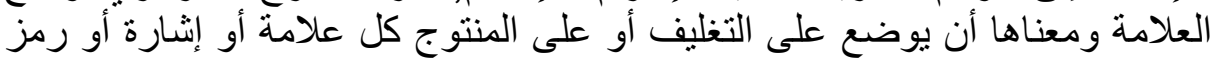

أو سمة أو شعار أو صورة أو بيان يحدد ميزة خاصة لمنتوج أو أو يميزه عن غيره(35). 
هذا ويمكن للمتدخل الإقتصادي أن يعلم المستهلك بأية طريقة أخرى مناسبة. (36)

وتجدر الإشارة إلى أن المشرع الجزائري أوجب أن تحرر بيانات الوسم و طريقة

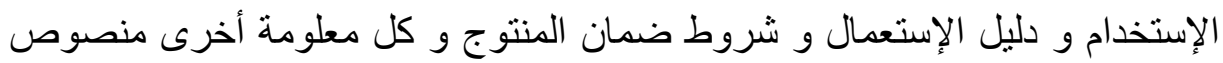

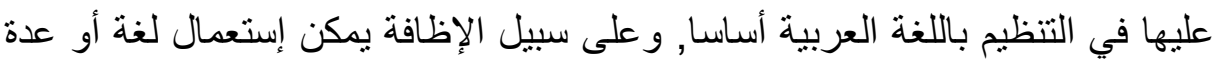

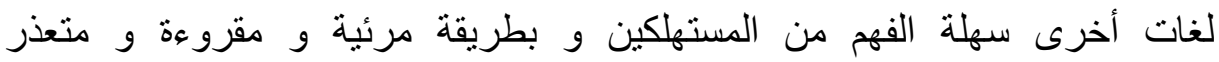
محو ها. (37)

ويكون المتدخل الإقتصادي موفي بإلتزامه بإعلام المستهلك ببيان الطريقة الصحيحة لإستعمال المبيع, ووفقا للغرض المخصص الإفي من من أجله و بحسب طبيعته(38).

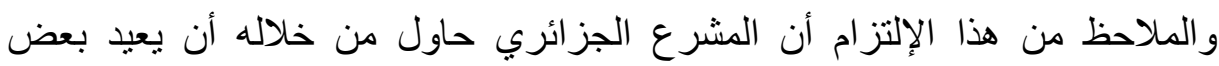

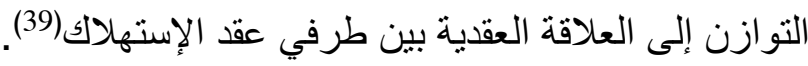
ثانيا: تقييد المتدخل بإلزامية الضمان

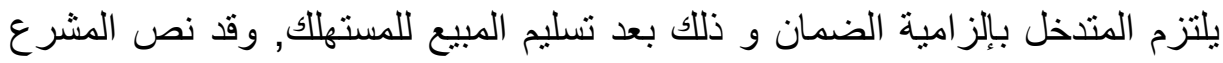

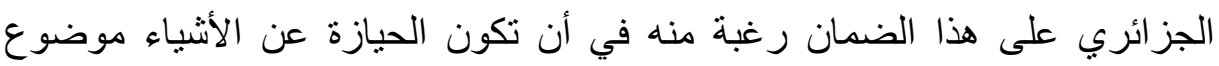

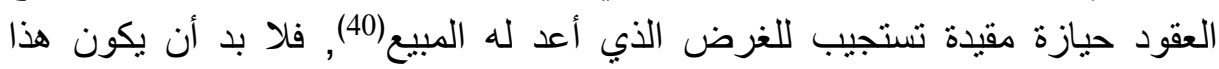

الأخير يحقق الغرض الذي قصده المستهلك من شر اءه(41). وقد نص المشرع على هذا الضمان في المواد 13 و 14 و 15 من قانون حماية المستهلك و قمع الغش و كذا في المرسوم التنفيذي 13-327 الذي يحدد شروط و كيفيات وضع السلع و الخدمات حيز التنفيذ(42), ومن خلال إستقراء هذه النصوص فئري نستنتج أن المشرع الجزائري أوجب على كل متدخل خلال فترة الضمان المحددة,

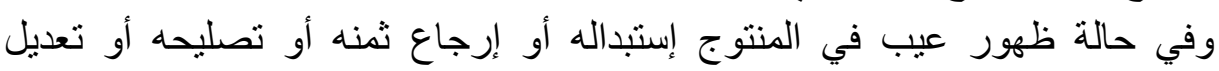
الخدمة على نفقته طبعا, بل أعتبر هذا الضمان من النظ النظام العام(43).

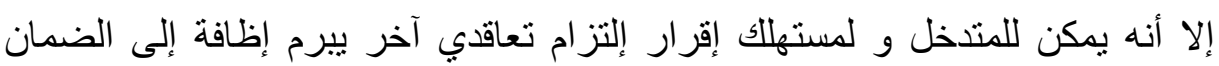

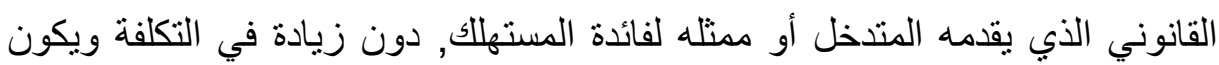
بمقابل أو مجانا و لا يلغي الإستفادة من الضمان الفئن القانوني (44).

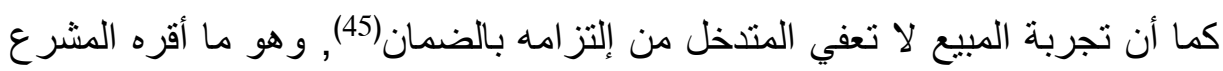
الجزائري صر احة في نص المادة 15 من قانون حماية المستهلك و قمع الغش و المادة 11 من المرسوم 13-13. و الملاحظ من هذا التقيد أنه ألم بعدة نقاط جوهرية تحمي المستهلك من عدة نواحي,

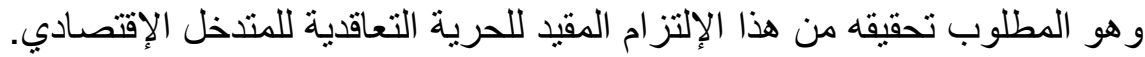

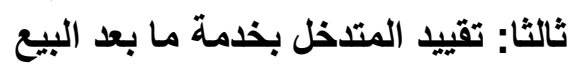

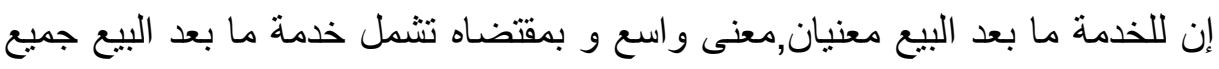

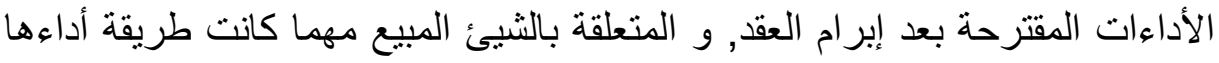

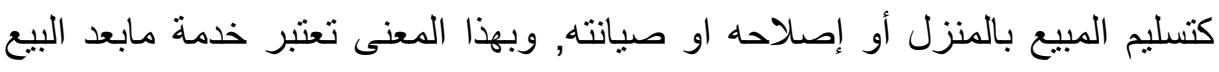


جزءا لا يتجزأ من الضمان القانوني أو الإتفاقي, أما المعنى الضيق لخدمة ما بعد البيع

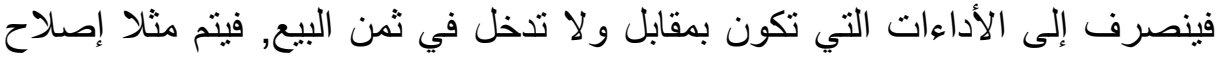

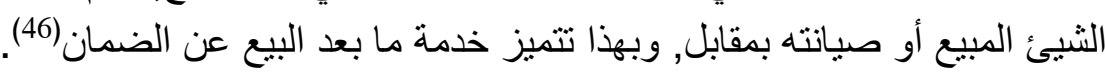
وقد نص المشرع الجزائري على هذه الخدمة في المادة 16 من قانون حماية المستهلك

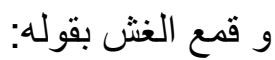

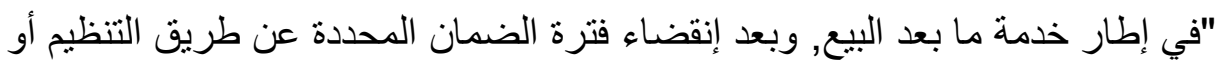

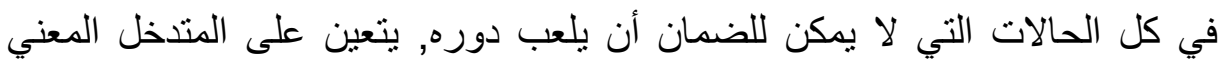

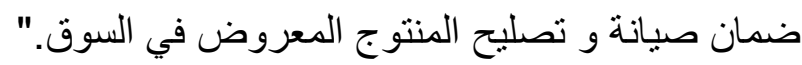

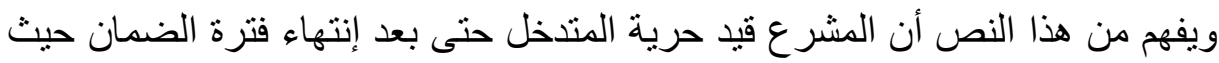

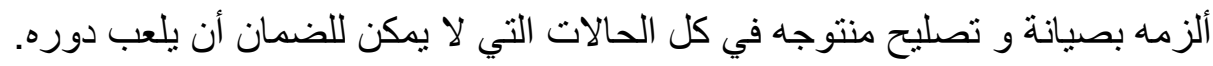
ولكن المشرع الجزائري لم ينص على أب جزاء يسري على ملى البائع في حالة إخلاله

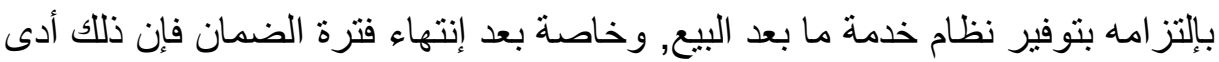
بلا شك إلى إفراغ نص المذكرر أعلاه من أية فائدة عملية(47).

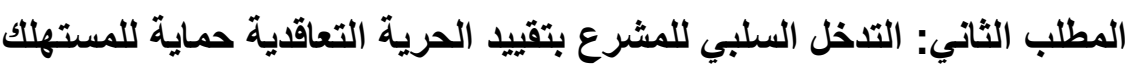

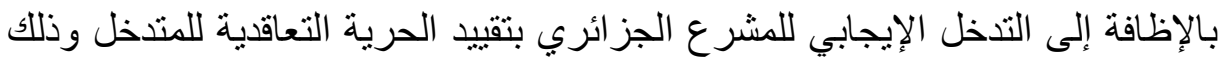

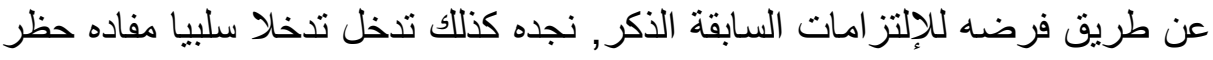

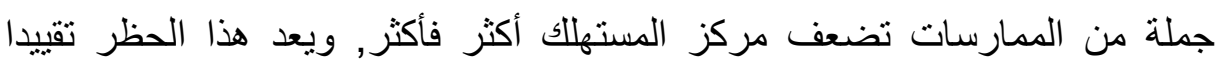
لحرية المتدخل الإقتصادي. وتتمثل هذه الممارسات المحظورة في الثروط التعسفية (الفرع الأول) و الإشهار

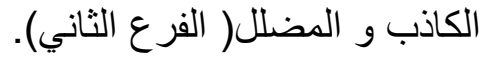

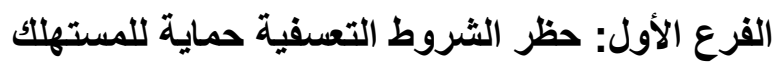

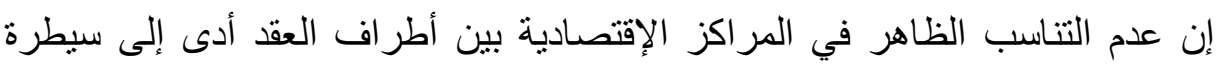

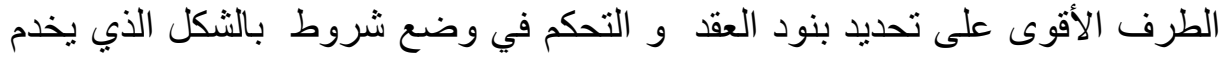
مصالحه, مهملا بذلك مصالح الطرف الضعيف الذي أصبح لا يستطيع حتى مناقثته فئه

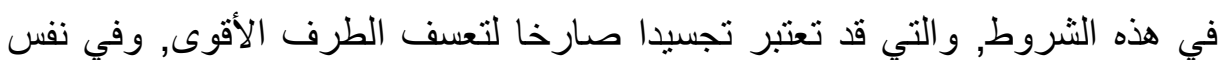

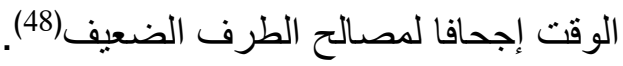

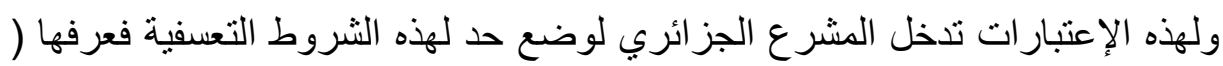

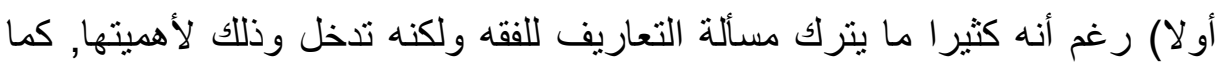
نجده قد ذكر عدة أمثلة عن هذه الثروط التعسفية (ثانيا) بل و أقر لجنة كاملة للحد من

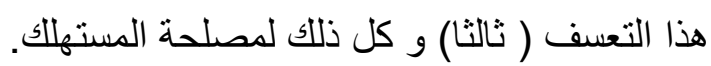
أولا: تعريف الثرط التعسفي

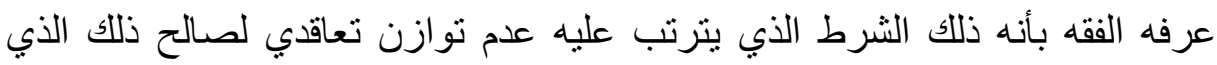

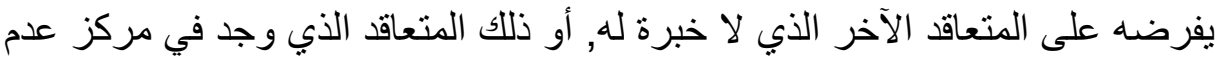

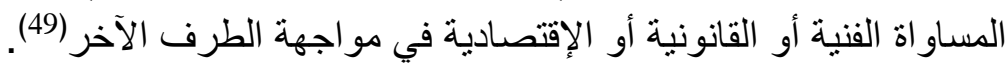
ونجد المشرع الجزائري قد نص هو الآخر على تعريف الثرط التعسفي وذللك في الفقرة الخامسة من المادة 03 من القانون رقم 
على الممارسات التجارية(50), فنص على أن الثرط التعسفي هو كل بند أو شرط

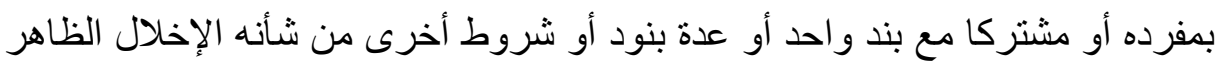
بالتوازن العقدي, أبي التوازن بين حقوق و و واجبات أطر اف واف العقد.

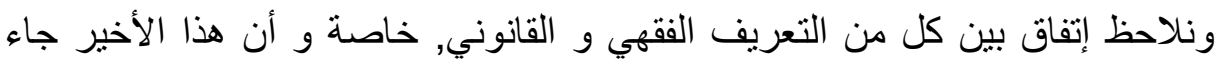
واسعاو و واضحاو صريحا و مفصلا.

\section{ثنانيا: أمثلة عن الثروط التعفية}

ومن أمثلة الثروط التعسفية الإنفراد بحقوق و إمتيازات لصالح المتدخل, وفرض التهاته

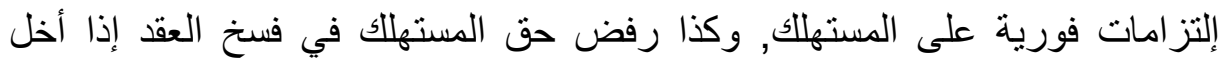

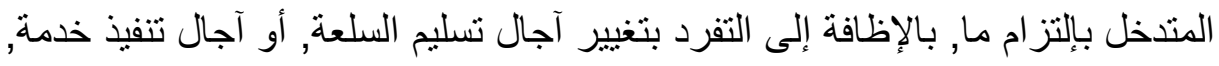
ومن الأمنلة كذللك تهديد المستهلك بقطع العلاقة التعاقدية لمجرد رفضه الخضه لثروط تجارية جديدة غير منكافئة(51). ثالثا: لجنة البنود التعسفية تختص هذه اللجنة بالبحث في كل العقود المطبقة من طرف الأعوان الإقتصاديين على لئى

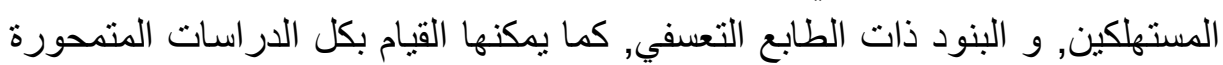
حول كيفية تطبيق العقود إتجاه الطرف الضعيف(52). وتتكون هذه اللجنة من خمسة أعضاء دائمين و خمسة أعضاء مستخلفين يتوزعون كمايأتي (53):

ـ ممثلان عن الوزير المكلف بالتجارة، مختصان في مجال الممارسات التجارية.

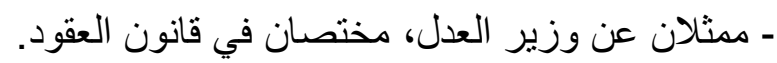
- ممثلان عن مجلس المنافسة. -متعاملان إقتصاديان بمثنان الغرفة الجزائرية للتجارة و الصناعة التهانة و مؤهلان في مجال قانون لأعمال و العقود. -ممثلان عن جمعيات حماية المستهلك مؤهلان في مجال قانون الاعمال و العقود. و ما يلاحظ على هذه اللجنة أنها تتدخل لصالح المستهلك وتسعى لحمايته من تعسف المتدخل الإقتصادي. وبما أن هذا الأخير هو الطرف الأقوى في العقد فإن مثل هكذا تدخل سيكون في غير

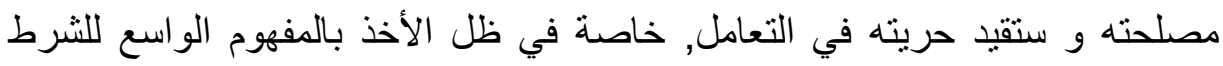
التعسفي(54). الفرع الثاني: حظر الإثهار الكاذب أو المضلل حماية للمستهلتك

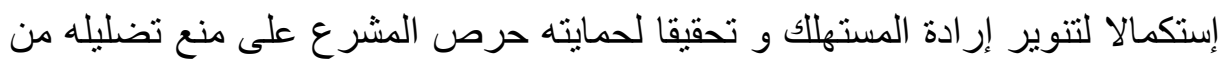

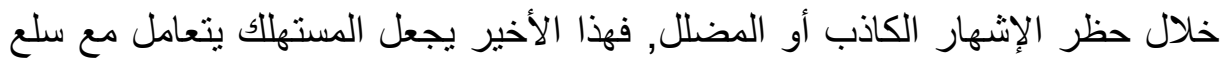

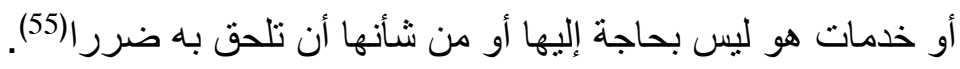
ويجب التنبيه إلى أن المشرع الجزائري لم يحظر الإشهار التجاري بل حظر الإشهار 
الكاذب و المضلل و سيتم تعريفه (أولا) و بيان محله (ثانيا) وكذا التطرق إلى (ثلى الإلتز امات المتعلقة بالإشهار (ثالثا).

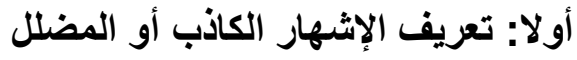

عرف الفقه الإعلان الكاذب بقوله: يكون الإعلان كاذبا منذ اللحظة التي لا تتطابق فيها

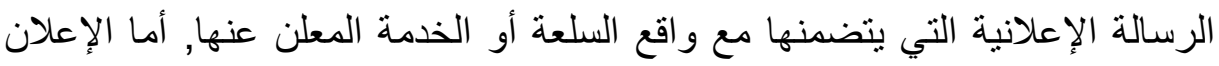

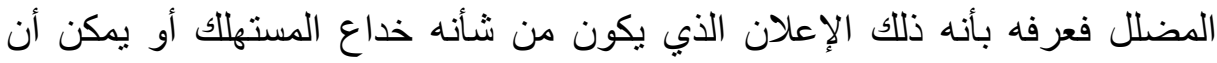

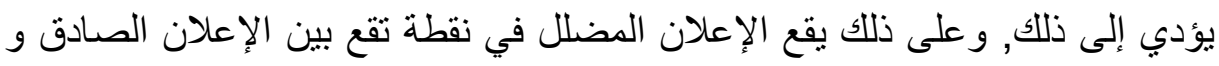
الإعلان الكاذب(56).

و الملاحظ أن الإعلان الكاذب يؤدي إلى التضليل و التضليل يكون بالكذب هما وجهان

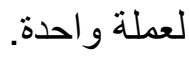
ثانيا: محل الكنب أو التضليل قد يتصل محل الكذب أو التضليل بالسلعة ذاتها أو الخدمة ذاتها, وقد يقع على عناصر

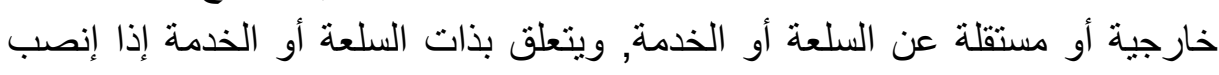

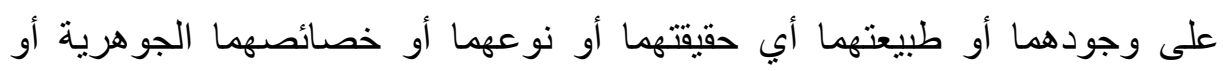
فائدتهما(57), وقد يتعلق الكذب أو التضليل بعناصر خارجية عن السلعة أو الخدمة, ويقصد بهذه العناصر كل الإعتبار ات التي تحيط بالسلعة أو الخدمة محل الإعلان دون

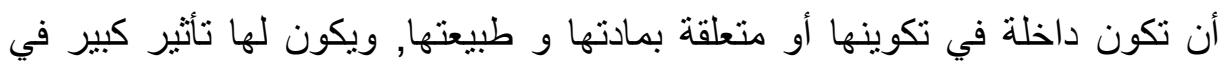

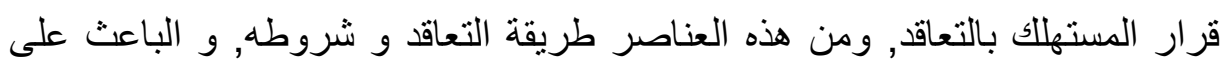
عرض السلعة أو الخدمة وكذا ثمنها (58). ثالثا: الإلتزمات المتعلقة بالإشهار نص المشرع الجزائري بموجب المرسومين التنفيذيين 91-101(59) 91103(60)على الإلتزامات المتعلقة بالإشهار, وقد تبنى من خلالها معظم المبادئ العامة الواردة في مدونة القواعد الدولية المرعية في مجال الإعلان تحت عنوان أخلاقيات

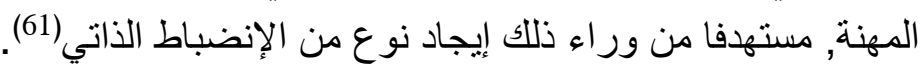
وقد نص المرسوم 101-91 على الإلتزامات المتعلقة بالإشهار في الفصل الخامس, أما المرسوم 103-91 فنص على ذلك في فصله الر ابع, و من هذه الإلتز امات:

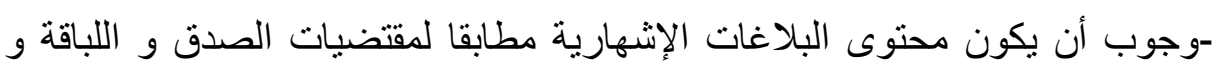

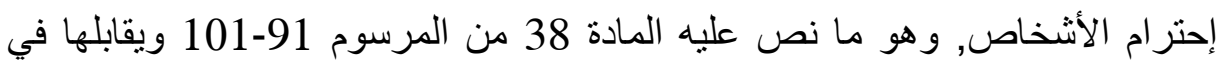

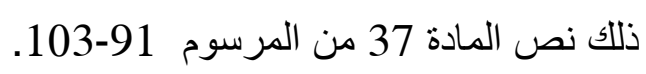
-وجوب أن تكون البلاغات الإشهارية خالية من جميع أنكال التمييز العنصري أو مأون

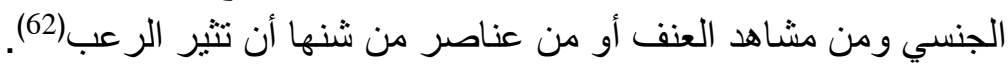
-وجوب أن لا تتضمن البلاغات الإشهارية من أي عنصر من شأنه المساس بالقناعات الدينية أو الفلسفية أو السياسية لاى لإن المشاهدين(63). -وجوب وضع تصور للإشهار في إطار إحترام مصالح المستهلكين ولا يجب 
تضليلهم (64).

و الملاحظ من هذا الإعلان الكاذب أو المضلل أنه يمثل إفسادا لإختيار المستهلكين و

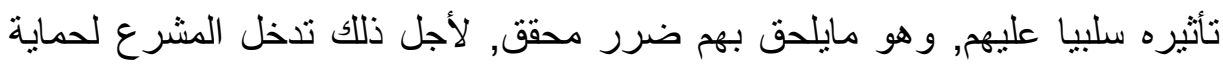
المستهلك من الوقوع في براثن الخديعة و حظر الإعلان الذي من شأنه تضليل هذا

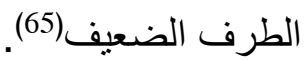

وبالرغم من خطورة هذا الإعلان الكاذب و المضلل إلا أنه لم يحضى من المشرع

الجزائري بأي تنظيم خاص من (66.

\section{خاتمة:}

بناء على نصوص المواد ماإرتبط منها بقانون حماية المستهلك و قمع الغش و لإنها

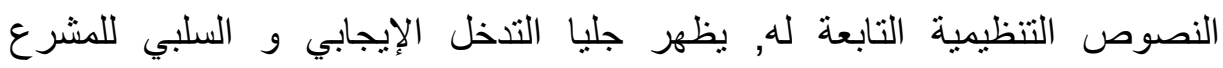

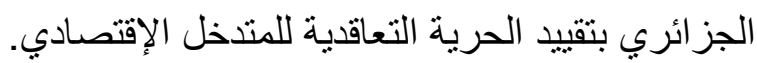

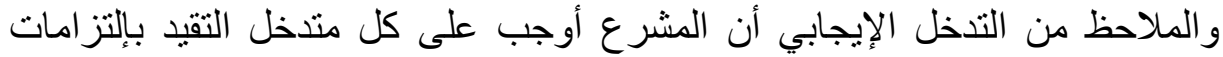

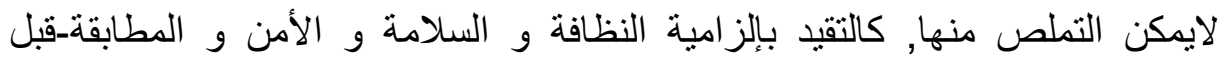

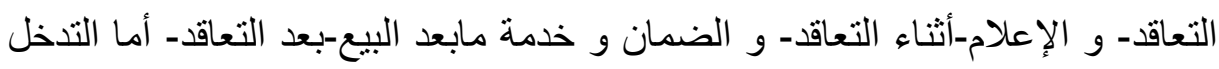

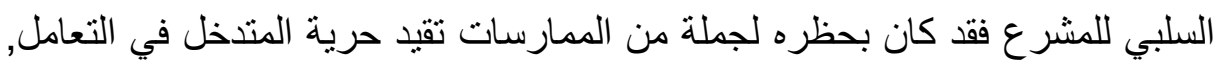
كالثروط التعسفية و الإشهار الكاذب أو المضلل, وكل هذا من أجل إعادة التوازن العقدي المفقود و المختل بين طرفي عقد الإستهلاك.

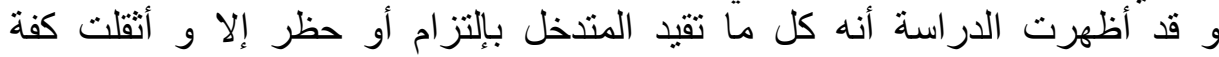

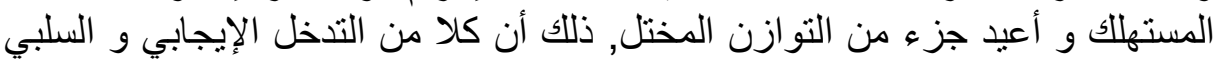

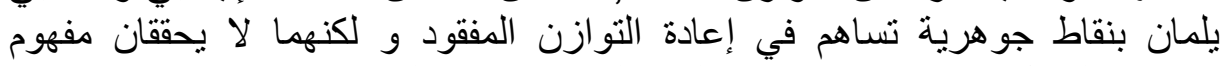
التوازن الكامل في المعرفة, وييقى المستهلك في حاجة إلى حماية مادامت الإلتزامات التات

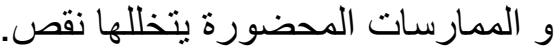

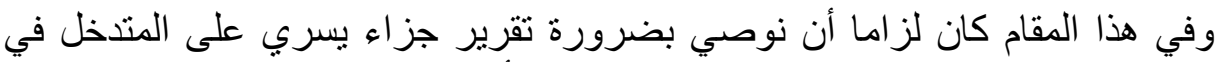

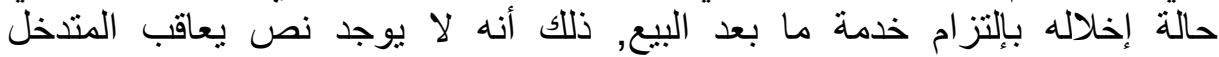

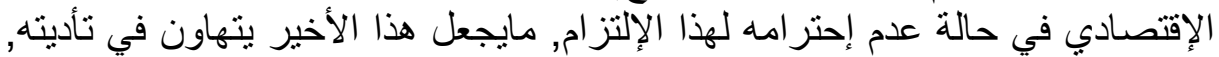

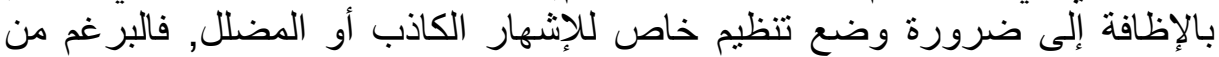

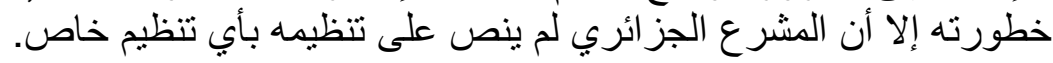


(1)-القانون رقم 09-03 ،المؤرخ في 25 فيفري لسنة 2009, يتعلق بحماية المستهلك و قمع الغش , ج رعدد 15 مؤرخة في

(2)- أنظر الفقرة الثانية من المادة 03 من المرسوم التنفيذي رقم 15-1408 المؤرخ في 11 أبريل

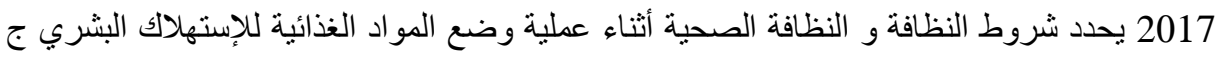

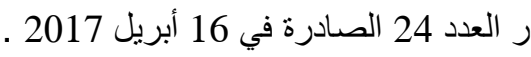
(3)- أنظر المادة 06 من القانون نفسه.

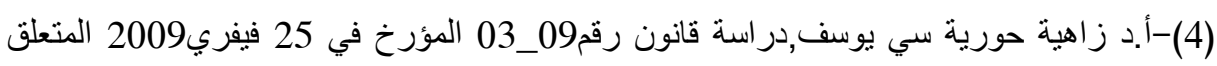

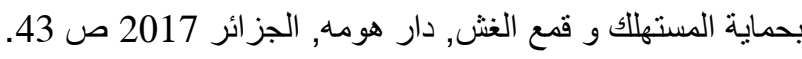
(5)- المرسوم التنفيذي رقم

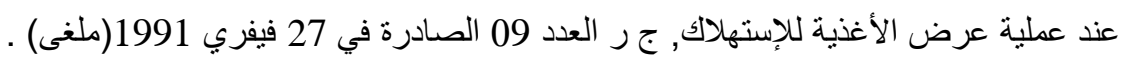
(6) - أنظر المادة 04 من القانون نفسه. (7)-المرسوم التنفيذي رقم 15-172 المؤرخ في 25 يونيو 2015 يحدد الثروط ون النئ الكيفيات المطبقة

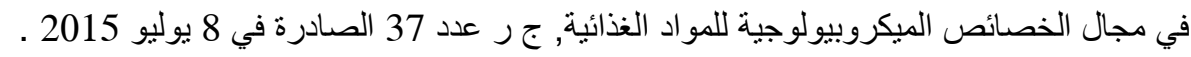
(8)-أنظر المادة 5 من القانون نفسه.

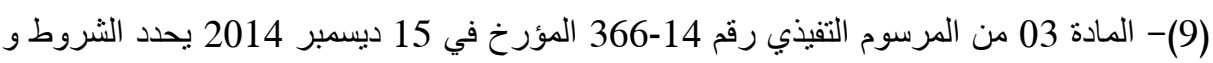
الكيفيات المطبقة في مجال الملوثات المسموح بها في المواد الغذائية, ج ر عد عد 74 الصنادرة في 25

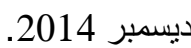

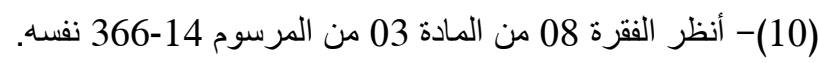
(11)- أنظر المادة 07 من القانون نفسه . (12)-المرسوم التنفيذي 04-210 المؤرخ في 28 جويلية 2004 يحدد كيفيات ضبط المونة المناصفات

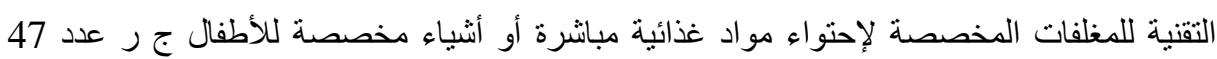

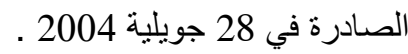
(13)-المرسوم التنفيذي رقم 94-04 المؤرخ في 19 جانفي 1991 يتعلق بالمو اد المعدة لكي تلامس

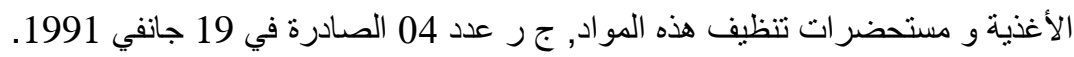

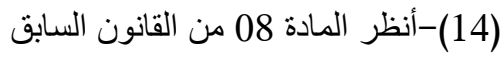

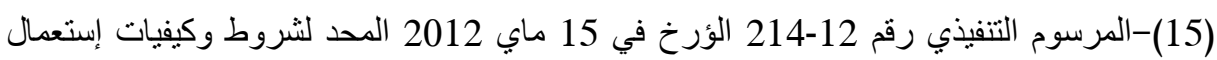

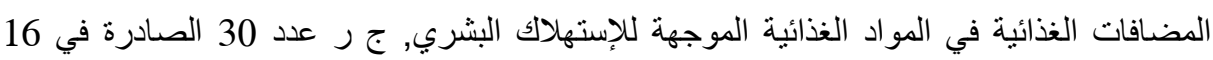
ماي 2012. (16)-لمزيد من التفصيل حول المنتوج المضمون أنظر الفقرة 12 من المادة 03 من القانون نفسه.

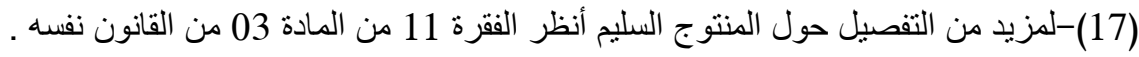
(18)-المرسوم التنفيذي رقم 12-203 المؤرخ في 06 ماي 2012 يتعلق بالقو اعد المطبقة في مجال

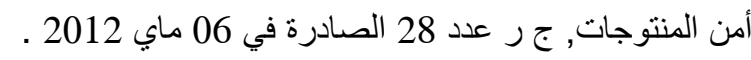
(19)- أنظر المادة 03 من المرسوم نفسـه.

(20)- د.محمد بودالي, حماية المستهلك في القانون المقارن در اسة مقارنة مع القانون الفرنسي، الفئ دار

$$
\text { الكتاب الحديث, الجزاير } 2006 \text { ص صدم } 283
$$
(21)- أنظر الفقرة 01 من المادة 11 من القانون نفسه. 


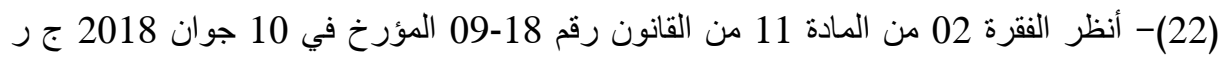
عدد 35 الصادرة في 13 جوان 2018 و الذي يعدل ويتمم القانون رقم

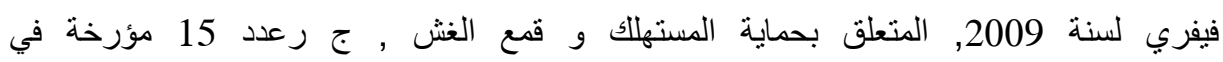
2009/08/08

$$
\text { (23)- أنظر الفقرة } 18 \text { من المادة } 03 \text { من القانون السابق. }
$$

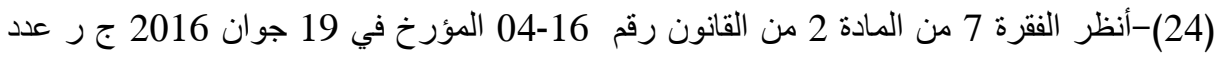

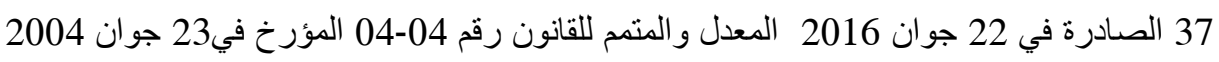
و المتعلق بالتقييس ج ر عدد 41 الصادرة في 23 جوان 23 جدان 2004.

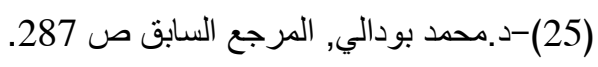

(26)-د. أسامة خيري, الرقابة و حماية المستهلك, دار الراية للنشر و التوزيع, الأردن 2015 ص صل صل

(27)-د. عبد المنعم موسى إبراهيم, حماية المستهلك, دراسة مقارنة, منشورات الحلبي الحقوقية, لبنان 2007 ص 372.

(28)-د. محمد بودالي, الإلتزام بالنصيحة في نطاق عقود الخدمات, دراسة مقارنة,دار الفجر للنشر و

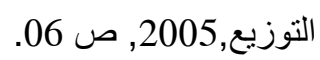
(29)-د. إبر اهيم بن داود, قانون حماية المستهلك, وفق أحكام القانون 09-03-03 المؤرخ في 25 فبر اير

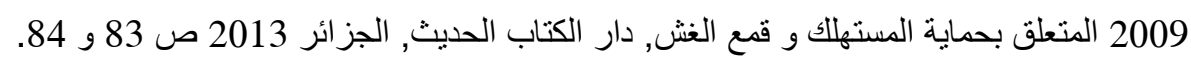

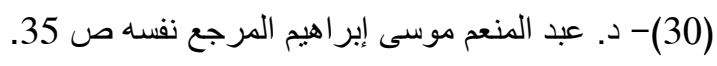
(31)- أنظر المادة 17 من القانون 09-03-03 نفسيه

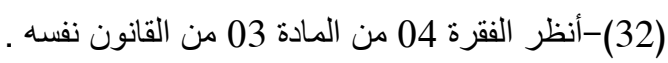

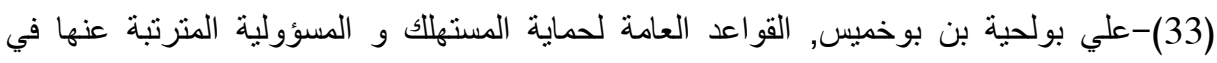

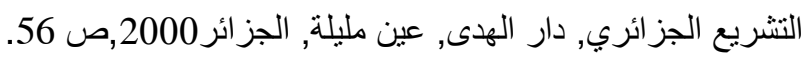

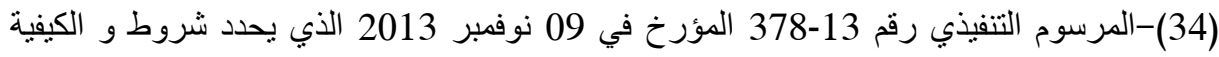

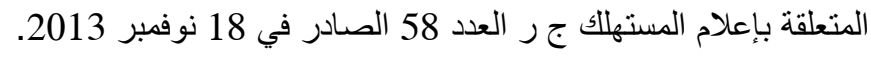

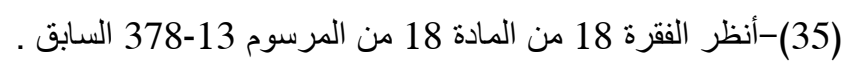

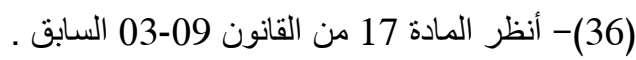
(37)-أنظر المادة 18 من القانون نفسه .

(38)-د.سه نكه ر علي رسول, حماية المستهلك وأحكامه, دراسة مقارنة, دار الفكر الجامعي, الإسكندرية2016 ص133. (39)-د. فاتن حسين حوى, الوجيز في قانون حماية المستهلك, منشورات الحلبي الحقوقية, لبنان 2012 ص60. (40)-أ. سليم سعداوي، حماية المستهلك الجزائر نمودجا، ط 1، دار الخلدونية، الجزائر2009ص

(41)-د. أنشرف محمد رزق قايد, حماية المستهلك, در اسة في قوانين حماية المستهلك والقو اعد العامة

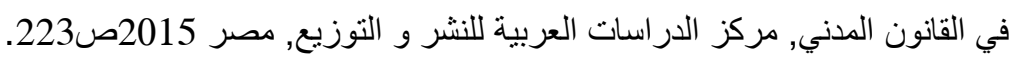


(42)- المرسوم التتفيذي 13-327 المؤرخ في26 سبتمبر 2013 يحد شروط و كيفيات وضع ضمان السلع و الخدمات حيز التنفيذ, جر العدد 49 الصادرة في 26 سبتمبر 2013 ـ. (43)-أنظر المادة 13 من القانون 09-03 نفسه. (44)-أنظر المادتين 3 و 14 من المرسوم نفسه.

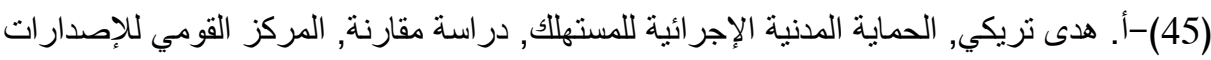
القانونية,الطبعة الأولى القاهرة, 2017 ص53. (46)-د.محمد بودالي, حماية المستهلك في القانون المقارن, المرجع السابق صالك 386.

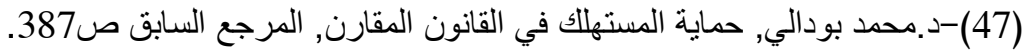
(48)-د. إبراهيم عبد العزيز داود,حماية المستهلك في مواجهة الثروط التعسفية, دراسة تحليلية مقارنة في ضوء نظريتي عقود الإذعان و عقود الإستهلاك, دار الجامعة الجديدية الإسكندرية 2014

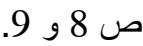
(49)-د. عمر محمد عبد الباقي, الحماية العقدية للمستهلك, دراسة مقارنة بين الثريعة و القانون,

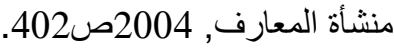
(50)-القانون 04-02 الوؤرخ في 23جوان 2004 يحدد القو اعد المطبقة على الممارسات التجارية, ج رعدد 41 الصادرة في 27 جوان2004 معدل و متمم بالقانون رقم 10-06 المؤرخ في 15 أوت التوات

$$
2010 \text { ج رعدد } 46 \text { الصادرة في181أوتأنظر المادة } 29 \text { من القانون 04-02010 السابق. }
$$

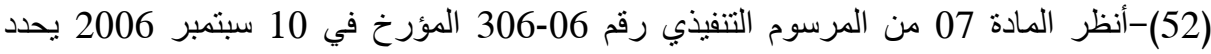

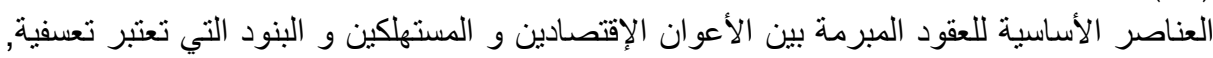

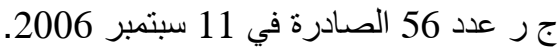
(53)- أنظر المادة 08 من المرسوم التتفيذي رقم 08-44 المؤرخ في 3 فيفري 2008 ج ر عدد 07 فين 06 الصادرة في 10 فيفري 2008 والمعدل للمرسوم التنفيذي رقم 06-306 المؤرخ في 10 سبتمبر 2006 الذي يحدد العناصر الأساسية للعقود المبرمة بين الأعوان الإقتصادين و المستهلكين و البنود

$$
\text { التي تعتبر تعسفية, جر عدد } 56 \text { الصادرة في } 11 \text { سبتمبر } 2006 .
$$

(54)-أ. أكرم محمد حسين التميمي,التظظيم القانوني للمهني, دراسة مقارنة في نطاق الأعمال

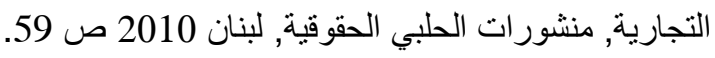

(55)-د. مصطفى أحمد أبو عمرو,موجز أحكام قانون حماية المستهلك, منشورات الحلبي الحقوقية,

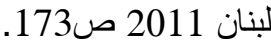
(56)-د. منى أبو بكر الصديق, الإلتزام بإعلام المستهلك عن المنتجات, دار الجامعة الجديدة, الإسكندرية ,2013,ص148 و 151. (57)-د. السيد محمد السيد عمران,حماية المستهلاك أثناء تكوين العقد, دراسة مقترنة مع دراسة تحليلية و نطبيقية لنصوص الخاصة بحماية المسنهلك, الدار الجامعية للطباعة و النشر بيروت 2003

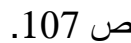

$$
\text { (58)-د. عمر محمد عبد الباقي, المرجع السابق ص } 149 .
$$

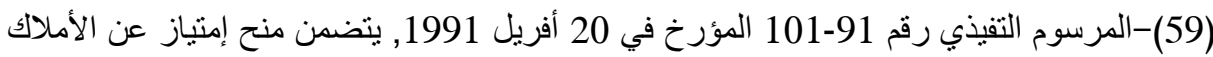
الوطنية و الصلاحيات و الأعمال المرتبطة بالخدمة العمومية للتلفزيون إلى المؤسسة العمومية للتلفزيون, جر عدد 19 الصادرة في 24 أفريل 1991 
(60)-المرسوم التتفيذي رقم 91-103 المؤرخ في 20أفريل 1991 يتضمن منح إمنياز عن الأملاك

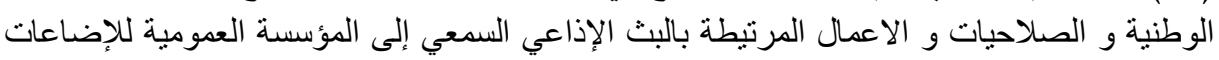

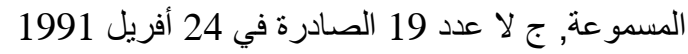

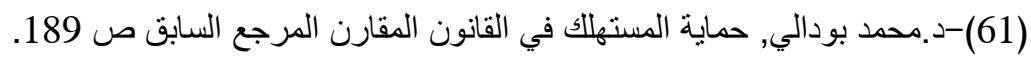

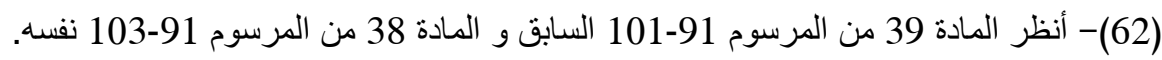

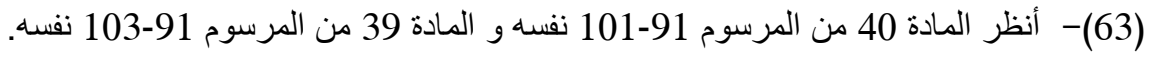

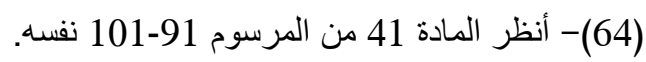
(65)-د. عبد الله حسين على محمود, حماية المستهلك من الغش التجاري و الصناعي, دراسة مقارنة,

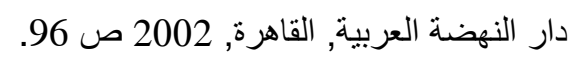

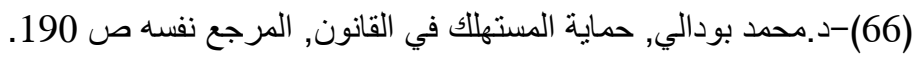

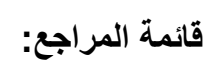

أولا: النصوص القانونية

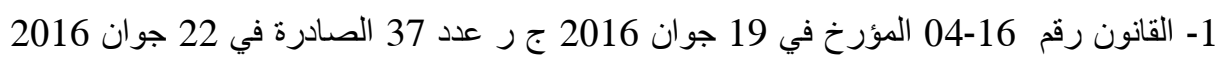

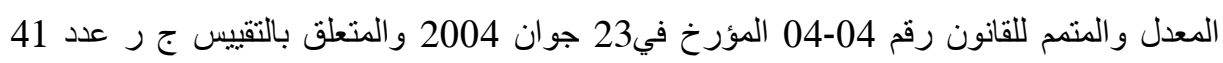

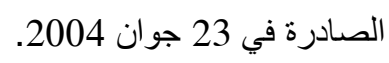
2- القانون 04-02 الوؤرخ في 23جوان فوان 2004 يحدد القو اعد المطبقة على الممارسات التجارية, ج

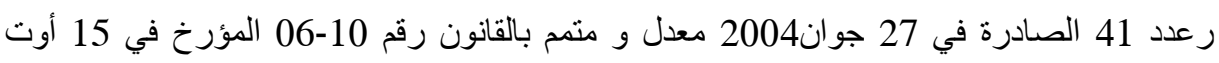

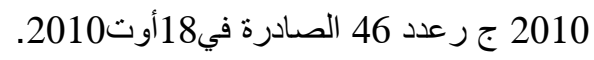
3- القانون رقم 2010 جرد 203 ،المؤرخ في 25 فيفري لسنة 2009, ينعلق بحماية المستهلاك و قمع الغش ,

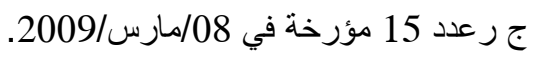
4- القانون رقم 18-09 المؤرخ في 10 جوان 2018 ج جر عدردان عدان 35 الصادرة في 13 جوان 2018 و الذي يعدل ويتمم القانون رقم 18

ثانيا: النصوص التنظيمية 1- المرسوم التنفيذي رقم 91-04 المؤرخ في 19 جانفي 1991 ينعلق بالمواد المعدة لكي تلامس

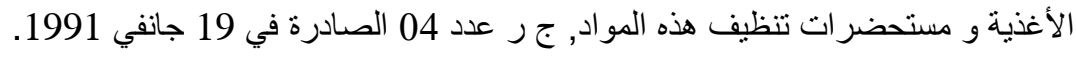

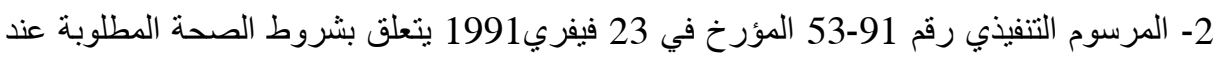

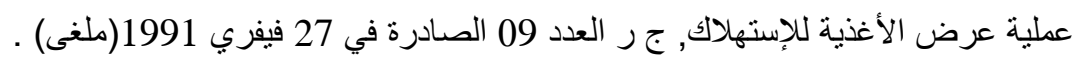

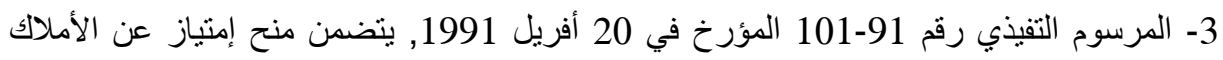
الوطنية و الصلاحيات و الأعمال المرتبطة بالخدمة العمومية للتلفزيون إلى المؤسسة العمومية التئية

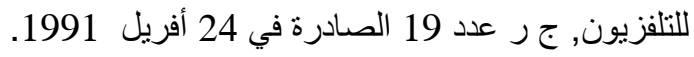

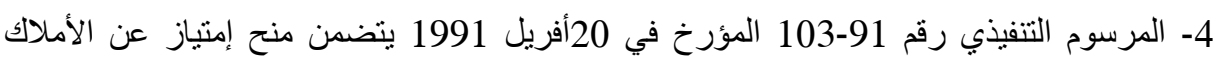

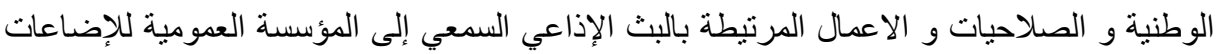

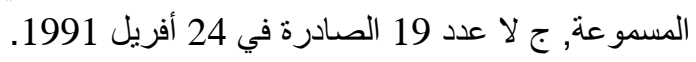


5- المرسوم التنفيذي 04-210 المؤرخ في 28 جويلية 2004 يحدد كيفيات ضبط المواصفات التقنية

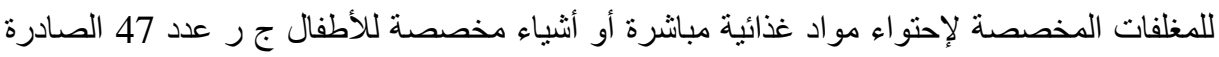
في 28 جويلية 2004 .

6- الدرسوم التنفيذي رقم 206-06 في 206 المؤرخ في 10 سبتمبر 2006 يحدد العناصر الأساسية للعقود المبرمة بين الأعوان الإقتصادين و المستهلكين و البنود التي تعتبر تعسفية, جر فر عدد 56 الصنادرة في

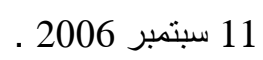

7- المرسوم التنفيذي رقم 08-44 المؤرخ في 3 فيفري 2008 ج ر عدد 07 الصادرة في 10 فيفري

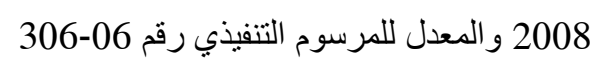
8- المرسوم التنفيذي رقم 12-203 المؤرخ في 06 ماي 2006 من 2012 ينعلق بالقواعد المطبقة في مجال

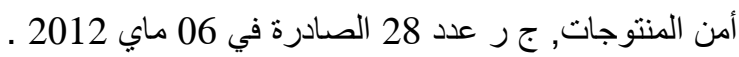

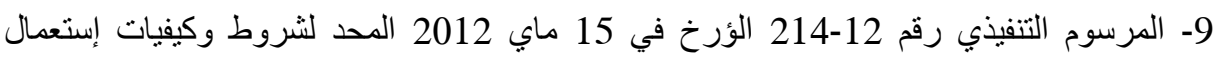

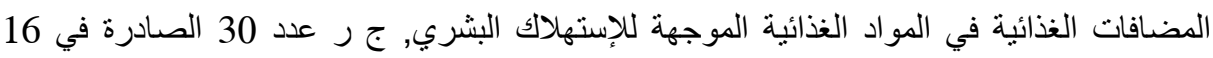
ماي 2012. 10- المرسوم التنيفيذي 13-327 المؤرخ في26 سبتمبر 2013 يحد شروط و كيفيات وضع ضمان السلع و الخدمات حيز التنفيذ, ج ر العدد 49 الصادرة في 26 سبتمبر 2013 ـ 2013 ـ

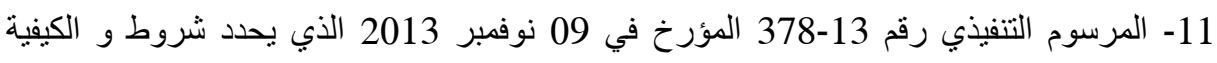

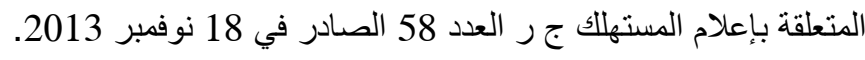

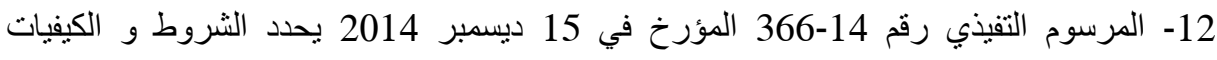
المطبقة في مجال الملوثات المسموح بها في المواد الغذائية, ج ر عدد 74 الصسادرة في 25 ديسمبر .2014 13- المرسوم التنفيذي رقم 15-172 المؤرخ في 25 يونيو 2015 يحدد الثروطو الكيفيات المطبقة

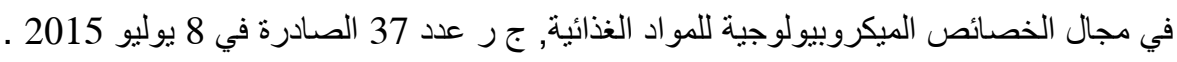
14- المرسوم التنفيذي رقم 14-140 المؤرخ في 11 أبريل 2017 يحدد شروط النظافة و النظافة الصحية أثناء عملية وضع المواد الغذائية للإستهلاك البشري جر ر العدي العد 24 الصادرة في 16 أبريل 1- د. السيد محمد السيد عمر ان,حماية المستهلك أثناء تكوين العقد, دراسة مقترنة مع دراسة تحليلية و تطبيقية لنصوص الخاصة بحماية المستهلك, الدار الجامعية للطباعة و النشر بيروت 2003. 2-أ. أكرم محمد حسين التميمي,التنظيم القانوني للمهني, دراسة مقارنة في نطاق الأعمال التجارية, منشور ات الحلبي الحقوقية, لبنان 2010.

3-د. أسامة خيري, الرقابة و حماية المستهلك, دار الر اية للنشر و التوزيع, الأردن 2015

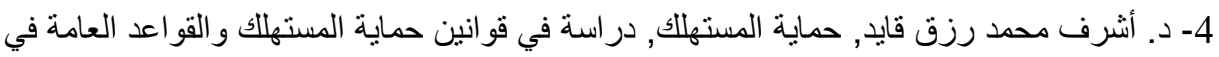

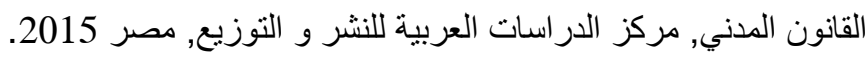

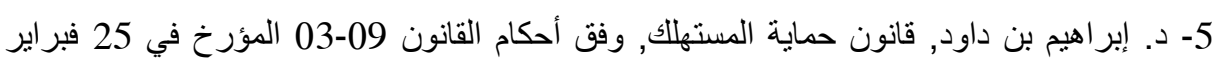
2009 المتعلق بحماية المستهلك و قمع الغش, دار الكتاب الحديث, الجزائر الركام 2013. 
6- د. إبراهيم عبد العزيز داود,حماية المنتهلك في مواجهة الثروط التعسفية, دراسة تحليلية مقارنة

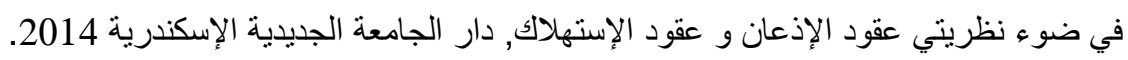

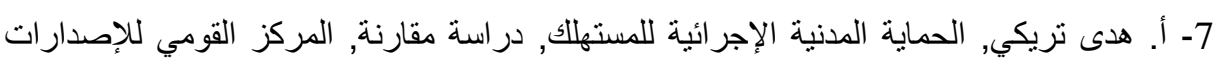

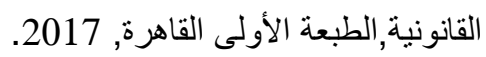

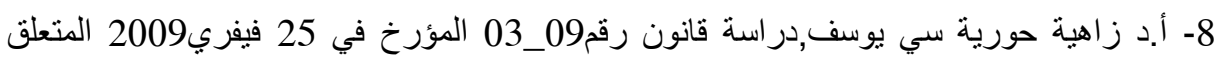

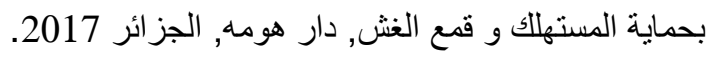
9- د. محمد بودالي, الإلتزام بالنصيحة في نطاق عقود الخدمات, دراسة مقارنة,دار الفجر للنشر و التوزيع,2005. 10- د. محمد بودالي, ، حماية المستهلك في القانون المقارن، دار الكتاب الحدبث، الجزائر، 2006. 11- د. مصطفى أحمد أبو عمرو,موجز أحكام قانون حماية المستهلك, منشورات الحلبي الحقوقية,

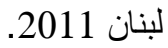
12- منى أبو بكر الصديق, الإلتزام بإعلام المستهلك عن المنتجات, دار الجامعة الجديدة, الإسكندرية, .2013

13- أ. سليم سعداوي، حماية المستهلك الجزائر نمودجا، ط 13، دار الخلدونية، الجزائر

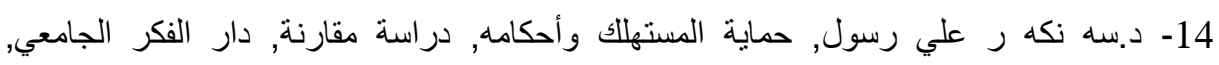
الإسكندرية2016.

15- علي بولحية بن بوخميس, القو اعد العامة لحماية المستهلك و المسؤولية المترتبة عنها في التشريع

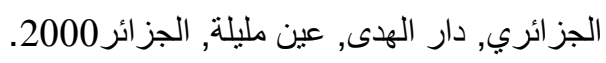
16- د. عبد الله حسين على محمود, حماية المستهلك من الغش التجاري و الصناعي, دراسة مقارنة, دار النهضة العربية, القاهرة, 2002. 17- د. عمر محمد عبد الباقي, الحماية العقدية للمستهلك, دراسة مقارنة بين الثريعة و القانون, منشأة

$$
\text { المعارف, } 2004 .
$$

18- د. عبد المنعم موسى إبراهيم, حماية المستهلاك, دراسة مقارنة, منشورات الحلبي الحقوقية, لبنان .2007

19- د. فاتن حسين حوى, الوجيز في قانون حماية المستهلك, منشورات الحلبي الحقوقية, لبنان 